\title{
EFFECT OF OUTFLOW CANNULA PLACEMENT AND PULSATILITY OF BLOOD PUMPS ON CEREBRAL BLOOD FLOW AND WALL SHEAR STRESS DURING CARDIAC ASSIST
}

\author{
T. A. S. Kaufmann ${ }^{1}$, T. Schmitz-Rode ${ }^{1}$, A. Moritz ${ }^{2}$, U. Steinseifer ${ }^{1}$ \\ ${ }^{1}$ Department of Cardiovascular Engineering, Institute of Applied Medical Engineering, \\ RWTH Aachen University, Aachen, Germany (kaufmann@ hia.rwth-aachen.de) \\ ${ }^{2}$ Department of Thoracic and Cardiovascular Surgery, J.W. Goethe University Hospital, \\ Frankfurt a.M., Germany
}

\begin{abstract}
Device cannulation to the cardiovascular system (CVS) is an important consideration for cardiac assist. Some devices return blood via the ascending aorta, while others place the outflow cannula in the descending aorta. A Computational Fluid Dynamics study in dependency on different flow profiles representing different devices was undertaken for both approaches. The main goal was to develop a computational model to analyze the impact of different parameters of Ventricular Assist Devices (VAD) support on flow conditions in general and cerebral perfusion in particular.
\end{abstract}

A $3 D$ model of the human CVS was reconstructed from Magnetic Resonance Imaging data. A $V A D$ outflow cannula was placed in four different positions inside ascending and proximal descending aorta. Transient numerical simulations were performed for each position assuming continuous and physiologically modulated device flow. The physiological flow from the heart was set to zero for a non-beating heart condition and $3 \mathrm{~L} / \mathrm{min}$ for a weak heart condition.

Main flow variables are only slightly affected by the cannulation method but highly affected by the flow profile. Wall shear stress is increased for pulsatile support, whereby arteriosclerotic plaque embolism might be induced. The cerebral blood flow is increased for cannulation of the descending aorta for each condition.

Keywords: Computational Fluid Dynamics, Ventricular Assist Devices, Outflow Cannula, Pulsatility, Cerebral Blood Flow. 


\section{INTRODUCTION}

In non-pulsatile applications such as many ventricular assist devices (VADs) or cardiopulmonary bypass (CPB) operations, the organ and tissue perfusion can be reduced by $20 \%$ [1-4]. In particular, the cerebral perfusion might be insufficient. Consequences of this condition are mnemonic problems, loss of neural functions or coma. Additionally, CPB patients have a higher risk for strokes [5, 6]. There are many possible reasons for those phenomena such as embolism [7], especially by the cannula jet hitting the aorta [8,9], or manipulation of the aorta [10-12]. Different cannulae have been developed to improve the cerebral perfusion $[13,14]$ and recent studies revealed that patients with continuous flow support have a higher survival rate than those with traditional pulsatile devices [15]. Still, the position of the outflow cannula influences the blood flow in the outgoing arteries and thus end organ perfusion. Device cannulation to the cardiovascular system (CVS) is therefore an important consideration for $\mathrm{CPB}$ and VADs.

Traditionally, the cannula returns blood to the ascending aorta in both applications. Some surgeons however prefer cannula positioning in the subclavian artery [16] during CPB. This technique has also received attention for the VAD application, due to the potential for a minimal invasive implantation approach [17]. Stenosis of the subclavian artery is a contra indicator for this method, and stenosis of the cerebral vessels has to be taken into account. Also, perfusion of the vertebral artery and thus the rear brain might be insufficient with this technique. Additionally, some VADs place the outflow cannula in the descending aorta.

The impact of the outflow cannula positioning for the CPB application has already been studied by means of computational fluid dynamics (CFD) and particle image velocimetry (PIV) $[18,19]$. The PIV validation revealed a variation of the simulations of less than $10 \%$. A continuative CFD study was initially undertaken to compare outflow cannula positioning in the ascending and descending aorta for the VAD approach. Different devices were represented by different flow profiles. Additionally, different interaction configurations between device and heart were analyzed.

\section{MATERIALS AND METHODS}

\subsection{Model creation}

As performed for the CPB application [18, 19], a 3-dimensional computer aided design (CAD) model of the CVS was generated from magnetic resonance imaging (MRI) records using the program package Mimics (Materialise Inc., Leuven, Belgium). The final model consisted of aorta, carotid, subclavian and vertebral arteries. The geometry of the heart valves was neglected. The final CAD model is shown in figure 1. 


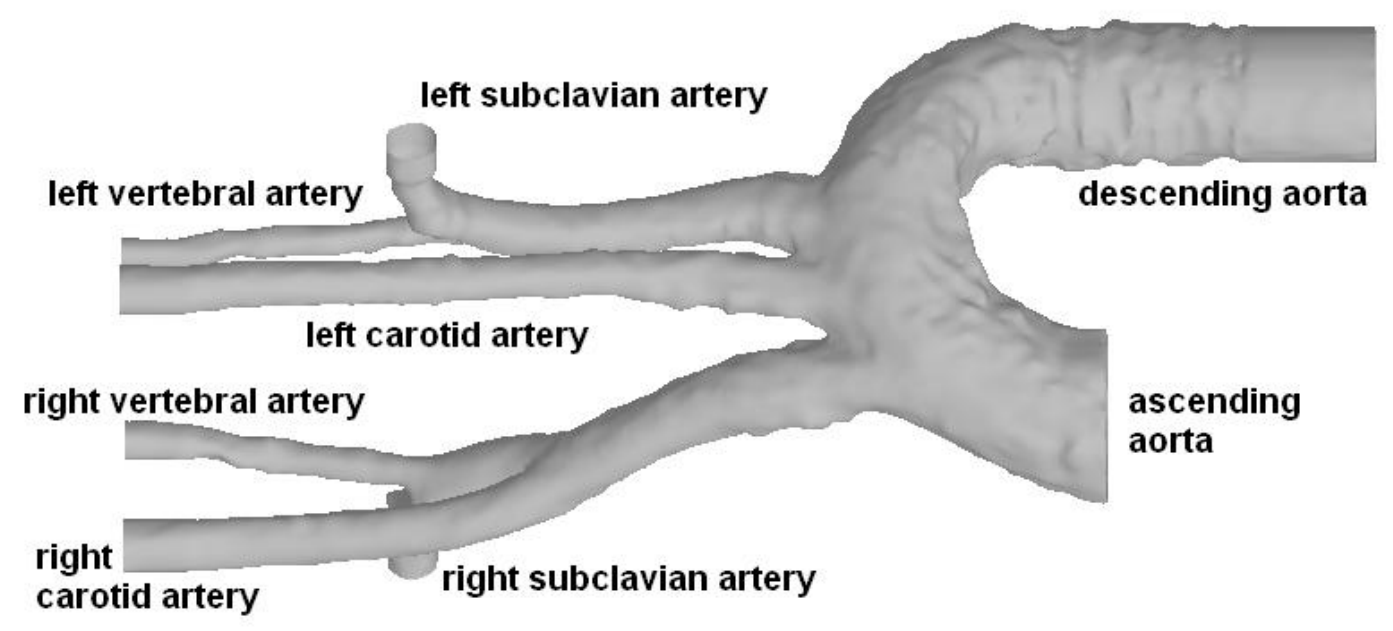

Figure 1. CAD model of the cardiovascular system.

In this CAD model, a 24 fr outflow cannula was virtually placed in four positions inside ascending (2) and proximal descending (2) aorta using the Computer Aided Engineering tool 3-matics (Materialise Inc., Leuven, Belgium).

For each position, a separate tetrahedral mesh was generated for the CFD analysis. Three layers of prism elements were created to resolve the boundary layers of the fluid. The final mesh consisted of approximately 1.5 million elements for each cannula position.

\subsection{Simulation}

Time dependent numerical simulations were performed with a timestep size of $0.01 \mathrm{~s}$ (ANSYS CFX 12.01, ANSYS Germany Inc., Otterfing, Germany). For the inlet boundary condition representing the heart (inlet_H), two different conditions were compared: A nonbeating heart and a weak beating heart. For the last case, a simplified flow profile was used assuming a cycle time of $1 \mathrm{~s}$ and a systolic time of $0.35 \mathrm{~s}$. The mass flow was scaled to 3 $\mathrm{L} / \mathrm{min}$. Since the geometry of the heart valve was neglected, the flow from the heart was assumed to be uniformed. The profile is depicted in figure 2 (inlet_H). 


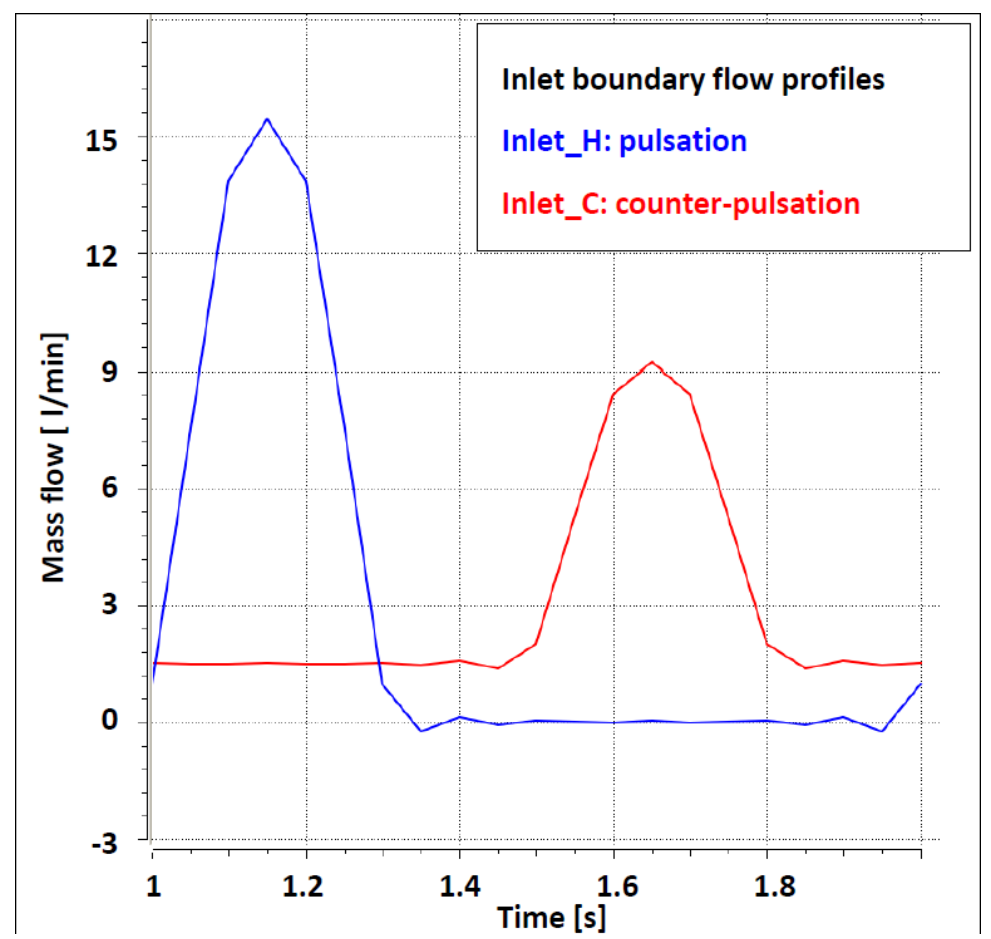

Figure 2. Simplified physiological flow profile and modulated pulsatile device profile.

Different inlet profiles representing different device types were compared for the cannula (inlet_C): continuous support (rotary pumps) and a similar pulsatility as assumed for inlet_H (membrane pumps). The pulsatile profile was run in synchronized and countersynchronized mode (figure 2, inlet_C) for the weak heart application. A flow of $3 \mathrm{~L} / \mathrm{min}$ was assumed for all different profiles at inlet_C for a weak beating heart. For a non-beating heart, $6 \mathrm{~L} / \mathrm{min}$ was set as the inflow boundary condition for inlet_C for both continuous and pulsatile support, so that a total flow of $6 \mathrm{~L} / \mathrm{min}$ was maintained in all cases. Additionally, preliminary studies for a $10 \%$ sine-form flow (roller pumps) were undertaken. Since the results were not significantly different from continuous support, they were neglected for further analysis.

While the physiological flow is laminar for most of the cycle, the peak systolic flow shows turbulent behavior. Thus, a shear stress transport turbulence model was used in the simulations. The aortic wall was assumed to be rigid and the vessels were set as openings with a static pressure of $55 \mathrm{~mm} \mathrm{Hg}$ and a pressure loss to represent systemic resistance [20]. Blood was modeled as a continuous, non-Newtonian fluid. The boundary settings of the simulations are shown in table 1 for a non-beating heart and table 2 for a weak heart.

Table 1. Simulation settings for a non-beating heart

\begin{tabular}{|c|c|c|c|}
\hline Notation & Type & Value & Options \\
\hline $\begin{array}{c}\text { Heart } \\
\text { (Inlet_H) }\end{array}$ & Inlet & $0 \mathrm{~L} / \mathrm{min}$ & - \\
\hline $\begin{array}{l}\text { Cannula } \\
\text { (Inlet_C) }\end{array}$ & Inlet & $6 \mathrm{~L} / \mathrm{min}$ & $\begin{array}{c}\text { Pulsation } \\
\text { Continuous flow }\end{array}$ \\
\hline Arteries & Opening & $55 \mathrm{~mm} \mathrm{Hg}$ & $\begin{array}{c}\text { Static pressure } \\
\text { Systemic resistance }\end{array}$ \\
\hline Wall & Wall & - & No slip, rigid \\
\hline
\end{tabular}


Table 2. Simulation settings for a weak beating heart

\begin{tabular}{|c|c|c|c|}
\hline Notation & Type & Value & Options \\
\hline $\begin{array}{c}\text { Heart } \\
\text { (Inlet_H) }\end{array}$ & Inlet & $3 \mathrm{~L} / \mathrm{min}$ & Pulsation \\
\hline $\begin{array}{l}\text { Cannula } \\
\text { (Inlet_C) }\end{array}$ & Inlet & $3 \mathrm{~L} / \mathrm{min}$ & $\begin{array}{c}\text { Synchronized pulsation } \\
\text { Counter-synchronized pulsation } \\
\text { Continuous flow }\end{array}$ \\
\hline Arteries & Opening & $55 \mathrm{~mm} \mathrm{Hg}$ & $\begin{array}{c}\text { Static pressure } \\
\text { Systemic resistance }\end{array}$ \\
\hline Wall & Wall & - & No slip, rigid \\
\hline
\end{tabular}

For the post processing (ANSYS CFX 12.01), the flow distribution, in particular the cerebral blood flow (CBF), pressure and velocities as well as wall shear (WSS) and shear strain rate (SSR) were analyzed and compared for each approach. All results were averaged from four cannula positions in the ascending and descending aorta, respectively.

\section{RESULTS}

The flow distributions for two of the four different cannula positions for a weak heart and continuous support for systole $(0.15 \mathrm{~s})$ and diastole $(0.60 \mathrm{~s})$ are depicted in figure 3.

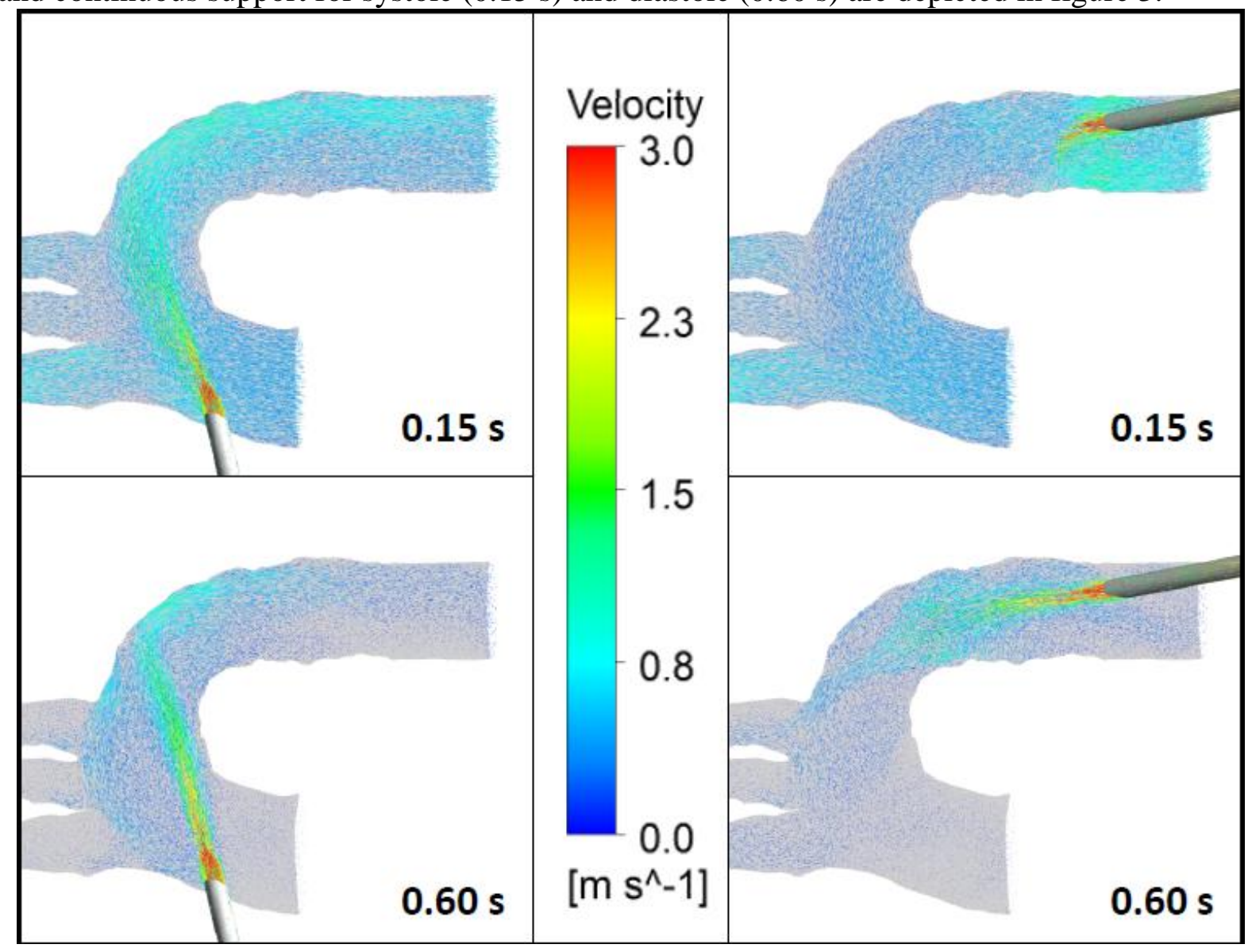

Figure 3. Flow distribution in the CVS for different cannula positions and time values. 


\subsection{VAD support for a non-beating heart}

Assuming a continuous device flow and a non-beating heart, the cerebral blood flow $(\mathrm{CBF})$ is $11.6 \%(\sim 0.70 \mathrm{~L} / \mathrm{min})$ of the total flow for cannulation of the ascending aorta. For cannulation of the descending aorta, $\mathrm{CBF}$ is increased by $\sim 1.2 \mathrm{l} /$ up to $32.7 \%$ of the total flow. The results for shear strain rate and pressure (max and average values) for this approach are shown in table 3. Pressure and WSS are increased for cannulation of the descending aorta.

Table 3. Non-beating heart, continuous device support

\begin{tabular}{|c|c|c|c|c|}
\hline Variable & $\begin{array}{c}\text { Asc. Aorta } \\
\text { cannulation } \\
\text { during systole }\end{array}$ & $\begin{array}{c}\text { Asc. Aorta } \\
\text { cannulation } \\
\text { during diastole }\end{array}$ & $\begin{array}{c}\text { Dsc. Aorta } \\
\text { cannulation } \\
\text { during systole }\end{array}$ & $\begin{array}{c}\text { Dsc. Aorta } \\
\text { cannulation } \\
\text { during diastole }\end{array}$ \\
\hline $\begin{array}{c}\text { Ave WSS } \\
{[\mathrm{Pa}]}\end{array}$ & 3.9 & 3.9 & 5.4 & 5.4 \\
\hline $\begin{array}{c}\text { Max WSS } \\
{[\mathrm{Pa}]}\end{array}$ & 109.3 & 109.6 & 132.8 & 131.8 \\
\hline $\begin{array}{c}\text { Ave SSR } \\
{[\mathrm{Pa}]}\end{array}$ & 254.3 & 253.4 & 334.1 & 333.9 \\
\hline $\begin{array}{c}\text { Max SSR } \\
{[\mathrm{Pa}]}\end{array}$ & 8341.5 & 8286.0 & 7521.0 & 7521.0 \\
\hline $\begin{array}{l}\text { Ave Velocity } \\
{[\mathrm{m} / \mathrm{s}]}\end{array}$ & 0.33 & 0.33 & 0.39 & 0.39 \\
\hline $\begin{array}{c}\text { Max Velocity } \\
{[\mathrm{m} / \mathrm{s}]}\end{array}$ & 5.86 & 5.87 & 5.94 & 5.94 \\
\hline $\begin{array}{c}\text { Ave Pressure } \\
{[\mathrm{mm} \mathrm{Hg}]}\end{array}$ & 57.9 & 57.9 & 59.13 & 59.13 \\
\hline $\begin{array}{c}\text { Max Pressure } \\
{[\mathrm{mm} \mathrm{Hg}]}\end{array}$ & 71.6 & 71.4 & 83.6 & 83.3 \\
\hline
\end{tabular}

Compared to the results for a continuous device flow, the average CBF is only slightly affected for a modulated pulsatile device profile. The time-dependent $\mathrm{CBF}$ is depicted in figure 4 . It is increased by $\sim 1 \mathrm{~L} / \mathrm{min}$ for cannulation of the descending aorta.

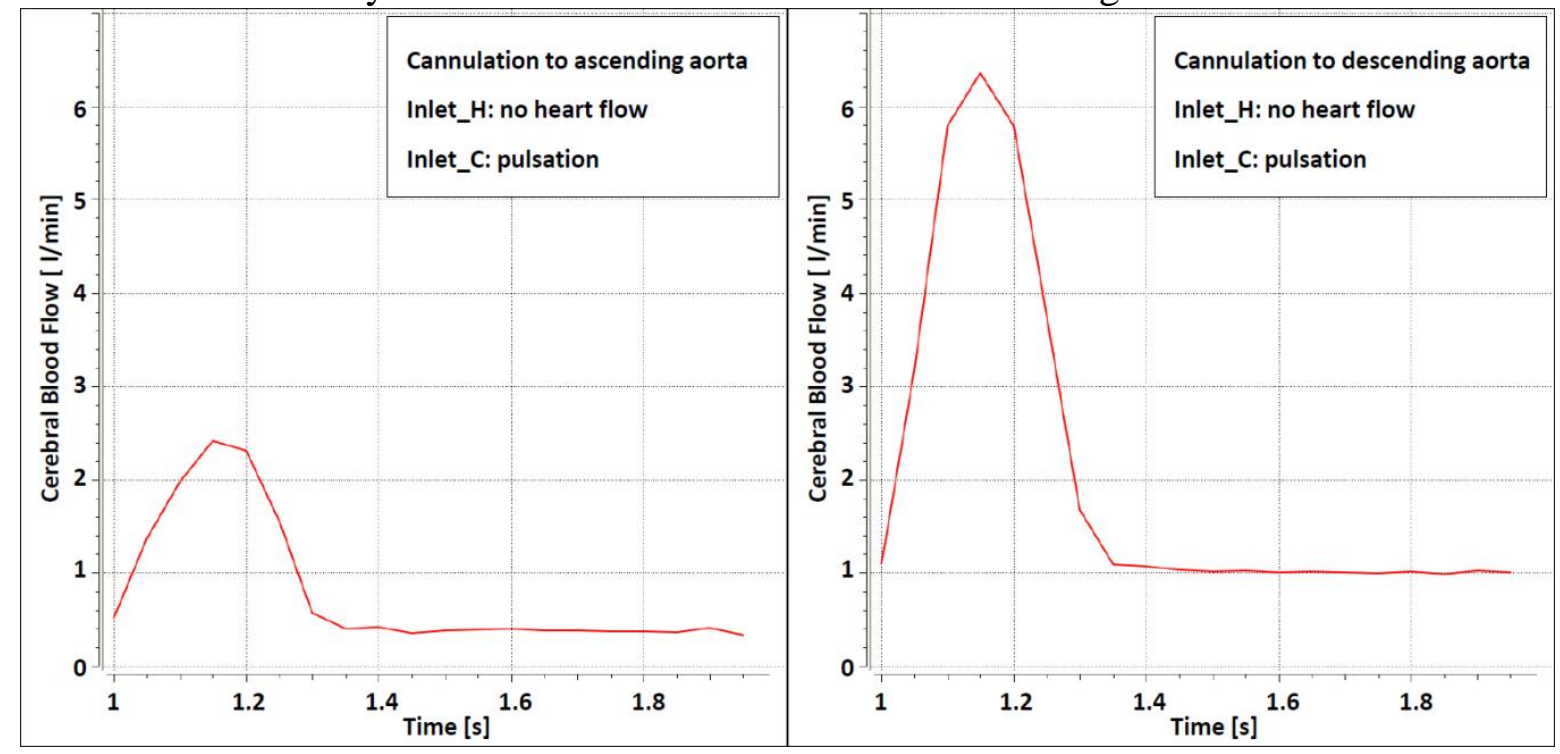

Figure 4. Cerebral blood flow for a non-beating heart and pulsatile device support. 
The corresponding flow variables are shown in table 4. Only pressure is affected by the cannula position. It is increased for cannulation of the descending aorta. However, SSR are about three times higher for pulsatile device support compared to constant flow, and WSS is even increased by a factor of approximately five.

Table 4. Non-beating heart, pulsatile device support

\begin{tabular}{|c|c|c|c|c|}
\hline Variable & $\begin{array}{c}\text { Asc. Aorta } \\
\text { cannulation } \\
\text { during systole }\end{array}$ & $\begin{array}{c}\text { Asc. Aorta } \\
\text { cannulation } \\
\text { during diastole }\end{array}$ & $\begin{array}{c}\text { Dsc. Aorta } \\
\text { cannulation } \\
\text { during systole }\end{array}$ & $\begin{array}{c}\text { Dsc. Aorta } \\
\text { cannulation } \\
\text { during diastole }\end{array}$ \\
\hline $\begin{array}{c}\text { Ave WSS } \\
{[\mathrm{Pa}]}\end{array}$ & 23.4 & 1.4 & 26.6 & 1.6 \\
\hline $\begin{array}{c}\text { Max WSS } \\
{[\mathrm{Pa}]}\end{array}$ & 473.7 & 44.9 & 644.5 & 54.2 \\
\hline $\begin{array}{c}\text { Ave SSR } \\
{[\mathrm{Pa}]}\end{array}$ & 623.1 & 134.1 & 695.4 & 147.0 \\
\hline $\begin{array}{c}\text { Max SSR } \\
{[\mathrm{Pa}]}\end{array}$ & 29285.0 & 3598.0 & 26815.0 & 3400.5 \\
\hline $\begin{array}{c}\text { Ave Velocity } \\
{[\mathrm{m} / \mathrm{s}]}\end{array}$ & 1.01 & 0.16 & 1.02 & 0.17 \\
\hline $\begin{array}{c}\text { Max Velocity } \\
{[\mathrm{m} / \mathrm{s}]}\end{array}$ & 17.1 & 3.07 & 17.65 & 3.09 \\
\hline $\begin{array}{l}\text { Ave Pressure } \\
{[\mathrm{mm} \mathrm{Hg}]}\end{array}$ & 81.0 & 55.7 & 117.1 & 56.65 \\
\hline $\begin{array}{c}\text { Max Pressure } \\
{[\mathrm{mm} \mathrm{Hg}]}\end{array}$ & 215.9 & 59.2 & 293.2 & 62.0 \\
\hline
\end{tabular}

\subsection{VAD support for a weak beating heart}

The CBF and flow variables for a weak heart and different device settings (continuous, synchronized pulsation, counter-synchronized pulsation) are presented in figures 5-7 and tables 5-7, respectively.

For a weak heart and continuous support, $\mathrm{CBF}$ is $\sim 1.1 \mathrm{~L} / \mathrm{min}$ for cannulation of the ascending aorta. This is slightly increased $(+0.4 \mathrm{~L} / \mathrm{min})$ for cannulation of the descending aorta (figure 5). 


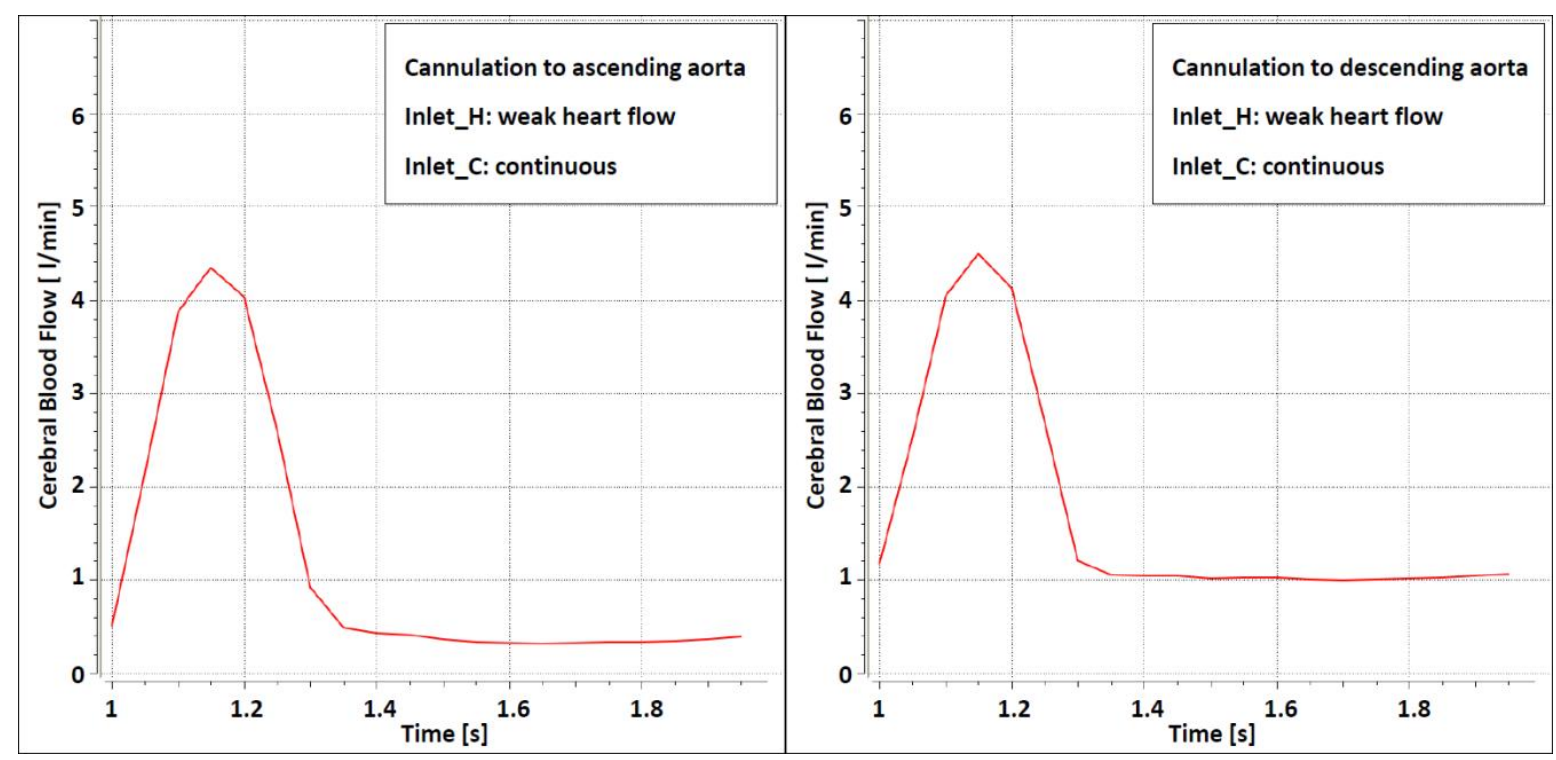

Figure 5. Cerebral blood flow for a weak heart and continuous device support.

The flow variables however are not significantly different for both approaches (table 5). However, SSR are lower than for a non-beating heart.

Table 5. Weak heart, continuous device support

\begin{tabular}{ccccc}
\hline Variable & $\begin{array}{c}\text { Asc. Aorta } \\
\text { cannulation } \\
\text { during systole }\end{array}$ & $\begin{array}{c}\text { Asc. Aorta } \\
\text { cannulation } \\
\text { during diastole }\end{array}$ & $\begin{array}{c}\text { Dsc. Aorta } \\
\text { cannulation } \\
\text { during systole }\end{array}$ & $\begin{array}{c}\text { Dsc. Aorta } \\
\text { cannulation } \\
\text { during diastole }\end{array}$ \\
\hline $\begin{array}{c}\text { Ave WSS } \\
\text { [Pa] }\end{array}$ & 3.9 & 1.32 & 3.9 & 1.44 \\
$\begin{array}{c}\text { Max WSS } \\
\text { [Pa] } \\
\text { Ave SSR } \\
{[\mathrm{Pa}]}\end{array}$ & 50.5 & 44.9 & 54.6 & 55.2 \\
$\begin{array}{c}\text { Max SSR } \\
{[\mathrm{Pa}]}\end{array}$ & 3628.5 & 3616.5 & 3308.5 & 3369.5 \\
$\begin{array}{c}\text { Ave Velocity } \\
{[\mathrm{m} / \mathrm{s}]}\end{array}$ & 0.42 & 0.15 & 0.40 & 0.15 \\
$\begin{array}{c}\text { Max Velocity } \\
{[\mathrm{m} / \mathrm{s}]}\end{array}$ & 3.13 & 3.09 & 3.08 & 3.12 \\
$\begin{array}{c}\text { Ave Pressure } \\
{[\mathrm{mm} \mathrm{Hg}]}\end{array}$ & 91.1 & 55.7 & 93.12 & 56.73 \\
$\begin{array}{c}\text { Max Pressure } \\
{[\mathrm{mm} \mathrm{Hg}]}\end{array}$ & 96.0 & 60.4 & 100.6 & 62.15 \\
\hline
\end{tabular}

The results for CBF do not change significantly for a weak heart and synchronized pulsatile device (figure 6). For cannulation of the ascending aorta, CBF is $\sim 1.0 \mathrm{~L} / \mathrm{min}$, while for cannulation of the descending aorta it equals $\sim 1.4 \mathrm{~L} / \mathrm{min}$. 


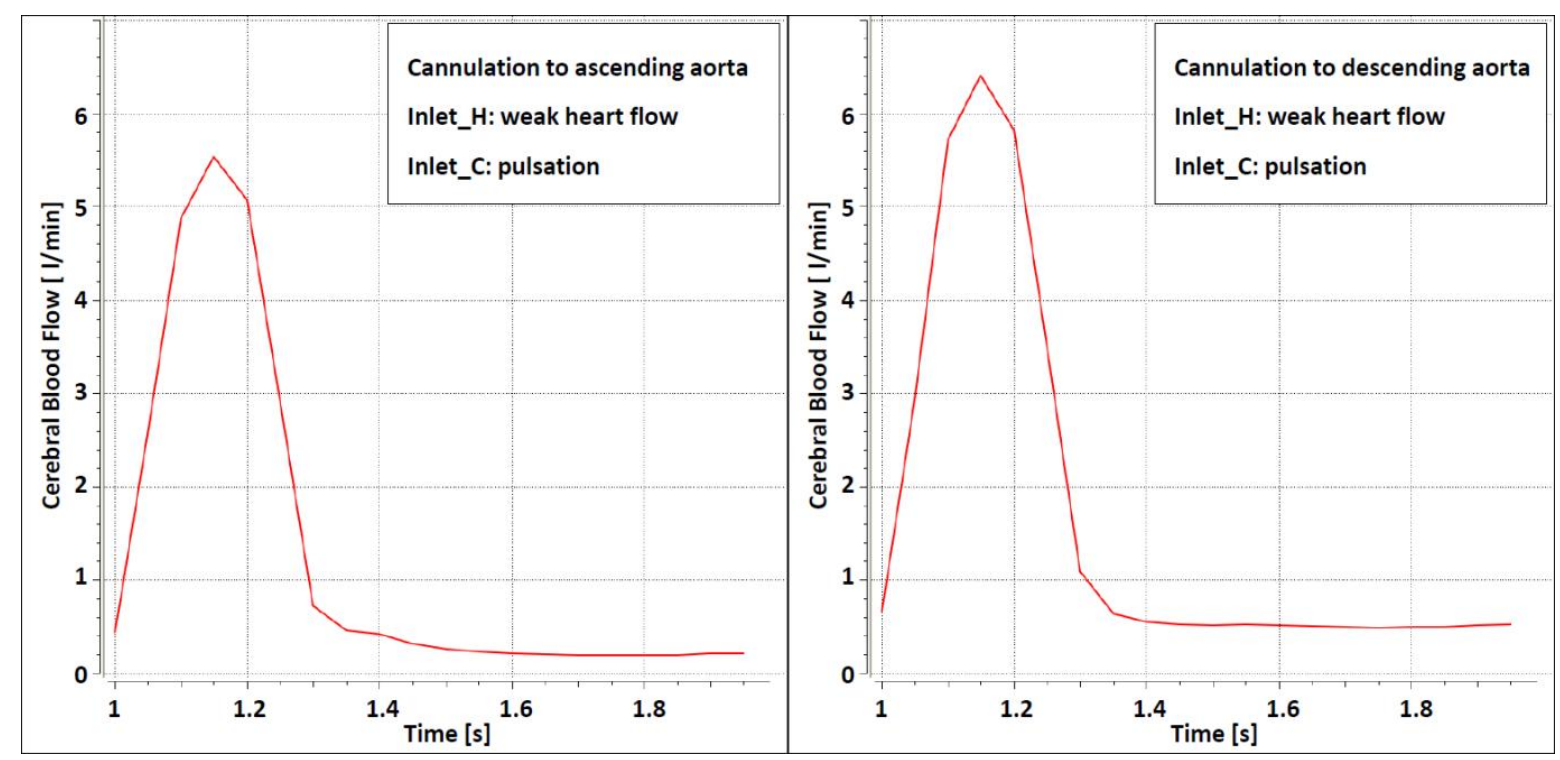

Figure 6. Cerebral blood flow for a weak heart and synchronized pulsatile device support.

The pressure in the CVS is again higher for cannulation of the descending aorta, as well as SSR by a factor of four and WSS by a factor of three (table 6). However, WSS and SSR are both lower than for a non-beating heart.

Table 6. Weak heart, synchronized pulsatile device support

\begin{tabular}{|c|c|c|c|c|}
\hline Variable & $\begin{array}{c}\text { Asc. Aorta } \\
\text { cannulation } \\
\text { during systole }\end{array}$ & $\begin{array}{c}\text { Asc. Aorta } \\
\text { cannulation } \\
\text { during diastole }\end{array}$ & $\begin{array}{c}\text { Dsc. Aorta } \\
\text { cannulation } \\
\text { during systole }\end{array}$ & $\begin{array}{c}\text { Dsc. Aorta } \\
\text { cannulation } \\
\text { during diastole }\end{array}$ \\
\hline $\begin{array}{c}\text { Ave WSS } \\
{[\mathrm{Pa}]}\end{array}$ & 10.4 & 0.5 & 10.3 & 0.6 \\
\hline $\begin{array}{c}\text { Max WSS } \\
{[\mathrm{Pa}]}\end{array}$ & 184.8 & 19.4 & 240.3 & 23.4 \\
\hline $\begin{array}{c}\text { Ave SSR } \\
{[\mathrm{Pa}]}\end{array}$ & 525.5 & 66.8 & 516.3 & 73.7 \\
\hline $\begin{array}{c}\text { Max SSR } \\
{[\mathrm{Pa}]}\end{array}$ & 12795.0 & 1639.5 & 13495.0 & 1656.5 \\
\hline $\begin{array}{c}\text { Ave Velocity } \\
{[\mathrm{m} / \mathrm{s}]}\end{array}$ & 0.70 & 0.08 & 0.66 & 0.08 \\
\hline $\begin{array}{c}\text { Max Velocity } \\
{[\mathrm{m} / \mathrm{s}]}\end{array}$ & 8.83 & 1.64 & 9.01 & 1.63 \\
\hline $\begin{array}{c}\text { Ave Pressure } \\
{[\mathrm{mm} \mathrm{Hg}]}\end{array}$ & 116.1 & 55.2 & 129.9 & 55.4 \\
\hline $\begin{array}{l}\text { Max Pressure } \\
{[\mathrm{mm} \mathrm{Hg}]}\end{array}$ & 162.6 & 56.3 & 171.3 & 56.7 \\
\hline
\end{tabular}

The total CBF for a counter-synchronized pulsatile profile and thereby an increased device flow during diastole is not different from the one for a synchronized pulsatile profile. However, the CBF during diastole is significantly increased, especially for cannulation of the descending aorta (figure 7). 

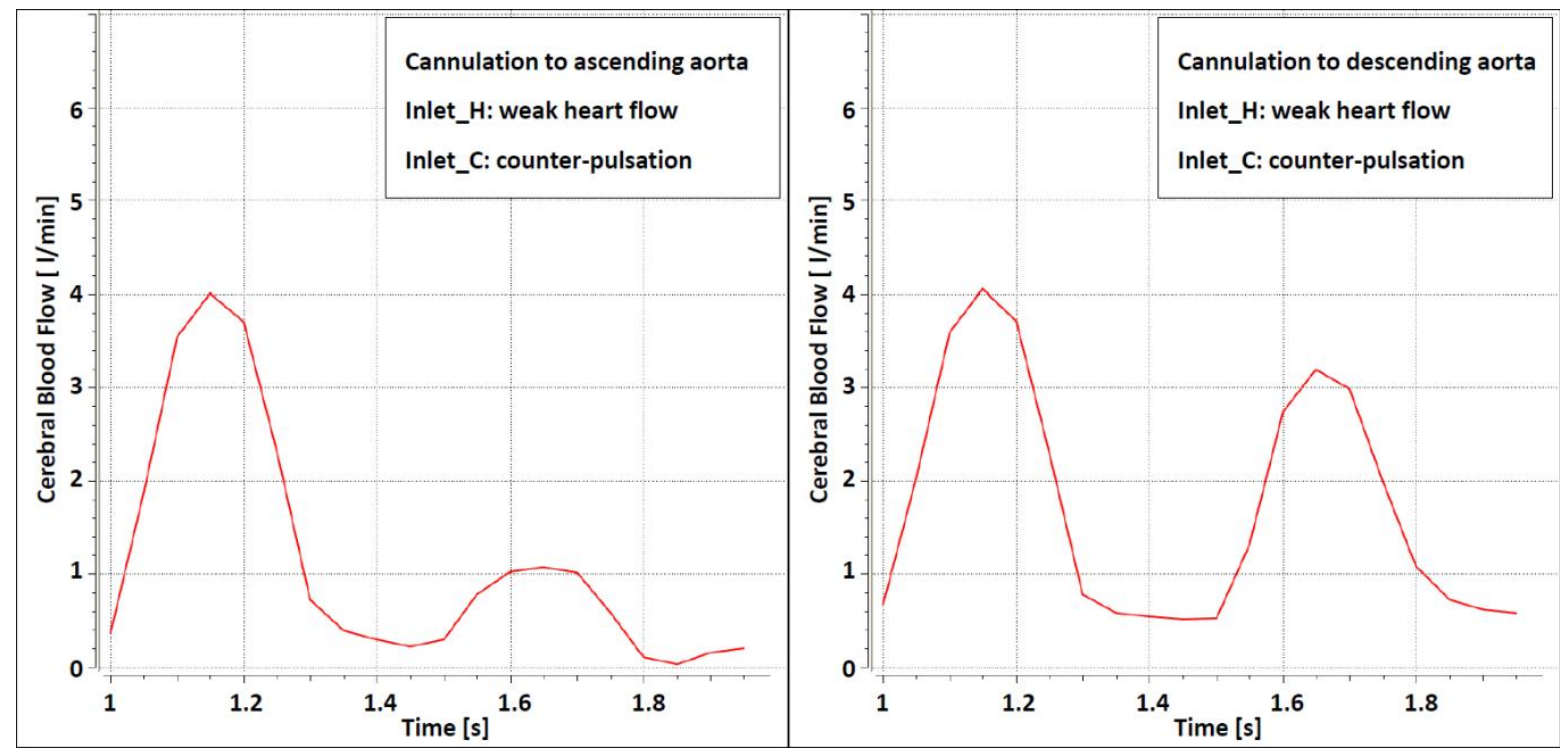

Figure 7. Cerebral blood flow for a weak heart and counter-synchronized pulsatile device support.

The maximum values of flow variables are shifted from systole to diastole for that approach. Furthermore WSS is decreased compared to synchronized support (table 7).

Table 7. Weak heart, counter-synchronized pulsatile device support

\begin{tabular}{ccccc}
\hline Variable & $\begin{array}{c}\text { Asc. Aorta } \\
\text { cannulation } \\
\text { during systole }\end{array}$ & $\begin{array}{c}\text { Asc. Aorta } \\
\text { cannulation } \\
\text { during diastole }\end{array}$ & $\begin{array}{c}\text { Dsc. Aorta } \\
\text { cannulation } \\
\text { during systole }\end{array}$ & $\begin{array}{c}\text { Dsc. Aorta } \\
\text { cannulation } \\
\text { during diastole }\end{array}$ \\
\hline $\begin{array}{c}\text { Ave WSS } \\
\text { [Pa] } \\
\text { Max WSS } \\
\quad \text { [Pa] }\end{array}$ & 3.0 & 5.4 & 3.0 & 5.8 \\
Ave SSR \\
$\quad 26.1$ & 162.5 & 23.7 & 205.1 \\
$\begin{array}{c}\text { Max SSR } \\
\text { [Pa] }\end{array}$ & 1883.0 & 11775.5 & 1906.0 & 11385.0 \\
$\begin{array}{c}\text { Ave Velocity } \\
{[\mathrm{m} / \mathrm{s}]}\end{array}$ & 0.37 & 0.36 & 0.35 & 0.36 \\
$\begin{array}{c}\text { Max Velocity } \\
{[\mathrm{m} / \mathrm{s}]}\end{array}$ & 1.72 & 8.06 & 1.63 & 8.21 \\
$\begin{array}{c}\text { Ave Pressure } \\
{[\mathrm{mm} \mathrm{Hg}]}\end{array}$ & 85.6 & 60.1 & 86.2 & 68.15 \\
$\begin{array}{c}\text { Max Pressure } \\
{[\mathrm{mm} \mathrm{Hg}]}\end{array}$ & 88.0 & 97.7 & 87.9 & 106.0 \\
\hline
\end{tabular}

\section{DISCUSSION}

Cerebral blood flow (CBF) is dependent on the cannula positioning approach. This is most significant for a continuous device flow and a non beating heart. However, CBF is always higher for cannulation of the descending aorta, as well as pressure and WSS. 
One reason for this phenomenon might be the cannula placement: for cannulation of the descending aorta, the cannula tip was placed towards the cerebral vessels, resulting in an increased flow in that direction and thereby an increased volume fraction and thus pressure. Additionally, the flow from the cannula acts as a resistance to the natural flow from the heart, at least for a weak beating heart. Thereby, more blood is distributed to the cerebral vessels. An increased flow to the coronary arteries is also likely, especially for the countersynchronized flow profile which provides an increased backflow during diastole, while the heart valve is closed. Analysis of these vessels is not implemented in the model yet. Therefore, further simulations with a new model that also includes the coronary arteries and the heart valve geometry are ongoing.

On the other hand, an increased CBF for cannulation of the descending aorta results in a decreased perfusion of the lower body. So for a patient with kidney failure, this cannula placement method might be dangerous. Consequently, the placement of the outflow cannula should be patient specific and based on the patients disease history and the chosen type of device.

One important finding of this study is that WSS is highly increased for pulsatile device flow. This carries the risk for arteriosclerotic plaque embolism, which is one of the main reasons for neurologic complications in CPB or VAD patients. The highest WSS occurred for a pulsatile device support and a non-beating heart. For this condition, a continuous flow device might reduce the risk for strokes due to plaque mobilization. For a weak beating heart, a counter-synchronized support decreases WSS. However, the lowest WSS occurs again for continuous flow.

Another problem which has not been addressed in this study is the possibility of emboli due to the cannula itself. For cannula placement in the descending aorta, the flow direction is pointed towards the carotid arteries and the brain. Thus, it is more likely for a thrombus to be shot directly to the brain, resulting in a stroke. This has to be considered for the cannula placement as well. So while CBF might be increased for cannula placement in the descending aorta, the risk for strokes might be increased as well.

These first results suggest that pulsatile flow has no significant effect on CBF while it increases WSS. It appears that pulsatile flow is therefore not necessary during cardiac assist. Moreover, even continuous flow devices provide a modulated pulsatile flow due to the pulsatility of the heart. This might add value to the ongoing discussion about continuous flow versus pulsatile flow devices.

There are however several limitations of this study so far. For the simulations, the aortic wall was assumed to be rigid, which is only valid for continuous support and a non-beating heart. Moreover, the vessels were set as openings with a static pressure and a systemic resistance, thus the complex autoregulation system of the body was assumed to be simplified and only velocity-dependent. This simplification has to be taken into account, and further model improvements are necessary. Therefore, fluid-structure-interaction simulations are planned to mimic the behavior of the aortic Windkessel function, and a mathematical model to represent the vascular resistance and thereby cerebral autoregulation is currently carried out [20]. Also, the impact of the blood distribution on microcirculation has not been taken into account. 
Moreover, each different device may have a different flow profile. Thus, actual flow profiles from clinically used devices need to be analyzed in order to provide valid guidelines for cannula placement.

Another crucial point is cannula design. A simplified design was chosen that has been successfully used in preliminary studies. However, many VADs use a graft for aortic blood return that has a higher diameter and thus a reduced jet. This might have an effect on the blood distribution. Therefore, simulations of different cannula and graft designs have to be performed in the future.

Beside these limitations, the developed model has proven to be able to analyze the effect of various parameters related to VAD outflow conditions. It can thus be transferred to specific VAD and patient conditions and can help to optimize the VAD support and system development at early development stages.

\section{CONCLUSION}

The flow conditions in the cardiovascular system were successfully simulated for different cannula inlet flow profiles representing different devices. The main flow variables in general and cerebral blood flow in particular could be analyzed.

The presented method provides the possibility of analyzing and optimizing the outflow conditions for individual patient data and different devices. It can thus help to decrease the risk of hypoperfusion and strokes, which are two of the main reasons for neurological problems during cardiopulmonary bypass and cardiac assist. However, the exact conditions for each device have to be studied, including cannula design and positioning as well as device related blood flow.

\section{REFERENCES}

[1] Hornick P., Taylor K., "Pulsatile and nonpulsatile perfusion: the continuing controversy". J Cardiothorac Vasc Anesth, 11(3):310-315, 1997

[2] Ji B., Undar A., "An evaluation of the benefits of pulsatile versus nonpulsatile perfusion during cardiopulmonary bypass procedures in pediatric and adult cardiac patients". ASAIO $J$, 52(4):357-361, 2006

[3] Tarcan O., Ozatik M. A., "Comparison of pulsatile and non-pulsatile cardiopulmonary bypass in patients with chronic obstructive pulmonary disease". Med Sci Monit, 10(7):CR294-CR299, 2004.

[4] Undar A., Ji B., "Detection and classification of gaseous microemboli during pulsatile and nonpulsatile perfusion in a simulated neonatal cpb model”. ASAIO J, 53(6):725-729, 2007.

[5] Grossi E. A., Kanchuger M. S., "Effect of cannula length on aortic arch flow: protection of 
the atheromatous aortic arch". Ann Thorac Surg, 59(3):710-712, 1995.

[6] Orime Y., Shiono M., "Cytokine and endothelial damage in pulsatile and nonpulsatile cardiopulmonary bypass". Artif Organs, 23(6):508-512, 1999.

[7] Bar-Yosef S., Anders M., "Aortic atheroma burden and cognitive dysfunction after coronary artery bypass graft surgery". Ann Thorac Surg, 78(5):1556-1562, 2004.

[8] Kapetanakis E. I., Stamou S. C., "The impact of aortic manipulation on neurologic outcomes after coronary artery bypass surgery: a risk-adjusted study". Ann Thorac Surg, 78(5):1564-1571.

[9] Undar A., Masai T., „Pulsatile and nonpulsatile flows can be quantified in terms of energy equivalent pressure during cardiopulmonary bypass for direct comparisons". ASAIO J, 45(6):610-614, 1999.

[10] Nakamura K., Harasaki H., "Comparison of pulsatile and non-pulsatile cardiopulmonary bypass on regional renal blood flow in sheep". Scand Cardiovasc J, 38(1):59-63, 2004.

[11] Scarborough J. E., White W., "Neurologic outcomes after coronary artery bypass grafting with and without cardiopulmonary bypass". Semin Thorac Cardiovasc Surg, 15(1):52$62,2003$.

[12] Verdonck P. R., Siller U., "Hydrodynamical comparison of aortic arch cannulae". Int J Artif Organs, 21(11):705-713.

[13] Albert A. A., Beller C. J., „Is there any impact of the shape of aortic end-hole cannula on stroke occurrence? clinical evaluation of straight and bent-tip aortic cannulae". Perfusion, 17(6):451-456, 2002.

[14] Joubert-Huebner E., Gerdes A., „An in vitro evaluation of a new cannula tip design compared with two clinically established cannula-tip designs regarding aortic arch vessel perfusion characteristics". Perfusion, 15(1):69-76, 2000.

[15] Fang J. C., "Rise of the machines-left ventricular assist devices as permanent therapy for advanced heart failure". N Engl J Med, 361(23):2282-2285, 2009.

[16] Gerdes A., Joubert-Hübner E., "Hydrodynamics of aortic arch vessels during perfusion through the right subclavian artery". Ann Thorac Surg, 69(5):1425-1430, 2000.

[17] Meyns B., Klotz S., "Proof of concept: hemodynamic response to long-term partial ventricular support with the synergy pocket micro-pump". J Am Coll Cardiol, 54(1):79-86, 2009.

[18] Kaufmann T. A., Hormes M., "The impact of aortic/subclavian outflow cannulation for 
cardiopulmonary bypass and cardiac support: a computational fluid dynamics study". Artif Organs, 33(9):727-732, 2009.

[19] Kaufmann T. A., Hormes M., "Flow distribution during cardiopulmonary bypass in dependency on the outflow cannula positioning". Artif Organs, 33(11):988-992, 2009.

[20] Kaufmann T. A., Schmitz-Rode T., "Mimicking of the Human Regulatory System by Flow-Dependent Vascular Resistance: A Feasibility Study”. Artif Organs, 0.1111/j.15251594.2011.01433.x, 2012. 